\title{
CoS nanosheets-coupled graphene quantum dots architectures as a binder-free counter electrode for high-performance DSSCs
}

\author{
Chang Yu, Zhiqiang Liu, Yiwen Chen, Xiangtong Meng, Mingyu Li and Jieshan Qiu*
}

\begin{abstract}
Hybrid materials with alternate components and synergetic effects are promising and intriguing materials as electrodes for high-performance energy storage/conversion devices. Cobalt sulphide (CoS) is one of the low-cost but inactive catalysts as counter electrode (CE) for dye-sensitized solar cells (DSSCs). How to optimize its structure and further enhance its electrochemical activity for $\mathrm{I}_{3}{ }^{-}$reduction remains a major challenge. Herein, a simple and efficient approach has been adopted to configure CoS sheets-coupled graphene quantum dots (GQDs) architectures via electrodepositing GQDs and CoS on the fluorine doped tin oxide glass substrate. When employed as the binder-free CE for DSSCs, the as-made CoS-GQDs exhibits a high catalytic activity towards the reduction of $\mathrm{I}_{3}{ }^{-}$, evidenced by the results of cyclic voltammetry (CV), electrochemical impedance spectroscopy (EIS), and Tafel polarization measurements. A conversion efficiency of $7.30 \%$ is achieved, being superior to $\mathrm{CoS} C E(5.55 \%)$ and Pt CE (6.94\%) due to their synergetic effects. The present work provides a simple method for configuring low-cost binder-free CE materials for replacing Pt.
\end{abstract}

Keywords: graphene quantum dots, cobalt sulphide, counter electrode, dye-sensitized solar cells

\section{INTRODUCTION}

Dye-sensitized solar cells (DSSCs), as potential and representative substitute for silicon-based solar cells, have triggered much attention due to low manufacturing cost, environmental friendliness, high conversion efficiency, and easy assembly [1-5]. DSSCs mainly consist of three main parts: a dye-sensitized nanocrystalline $\mathrm{TiO}_{2}$ photoanode, electrolyte such as the triiodide and iodide $\left(\mathrm{I}_{3}^{-} / \mathrm{I}^{-}\right)$solution, and counter electrode (CE) which is the most often-used Pt. The CE plays an important role in catalyzing the reduction of $\mathrm{I}_{3}^{-}$to maintain a steady power output. However, $\mathrm{Pt}$ is a noble metal with high expense and low storage, which will extensively limit the mass production and practical application of DSSCs. With this information, various materi- als as candidates are considered and developed to replace Pt CE, such as sulphide [6,7], nitride [8], polymer [9], carbon materials $[5,10,11]$, and hybrid materials [12].

Low-cost abundant cobalt sulphide $(\mathrm{CoS})$ is one of the potential and promising electrocatalysts which has been widely utilized in various energy storage/conversion devices such as Li-ion battery, supercapacitor [13-15], etc. It was also found that CoS as CE for DSSCs is capable of catalyzing the reduction of $\mathrm{I}_{3}{ }^{-}$. Nevertheless, its catalytic activity still needs to be further improved. Various efforts have been dedicated to modulating the structure of $\mathrm{CoS}$, thus increasing its catalytic activities. Miao et al. [16] deposited well-dispersed $\mathrm{CoS}$ nanoparticles on functional graphene nanosheets with high conductivity via electrodeposition and chemical bath process to replace Pt electrode, indicative of a comparable efficiency to Pt. Kung et al. [17] carried out a two-step approach of chemical bath deposition (CBD) and sulfuration treatment to fabricate acicular CoS nanorod arrays. This new morphology and structure endowed the DSSCs based on CoS CE with a good efficiency. It is easily observed that the size and morphology of CoS have an important influence on electrochemical performance for $\mathrm{I}_{3}^{-}$reduction, and carbon species have unique features and superiorities in increasing the conductivity of CoS CE materials, thus further improving its catalytic activities for $\mathrm{I}_{3}{ }^{-}$reduction.

Carbon quantum dots (CQDs), nano-sized carbon particles, have attracted growing interest due to their high photochemical stability, low toxicity, good biocompatibility, and low environmental impact $[18,19]$. It has also been demonstrated that CQDs are of great potential in energy storage and conversions [20-22]. It is well known that there are abundant negative charged oxygen-containing functional groups on the surface of CQDs. These groups could further adsorb metal ions with positive charge easily to

State Key Lab of Fine Chemicals, Liaoning Key Lab for Energy Materials and Chemical Engineering, PSU-DUT Joint Center for Energy Research, Dalian University of Technology, Dalian 116024, China

"Corresponding author (email: carbon@dlut.edu.cn) 
modulate their structure each other. Chen et al. [20] firstly used graphene quantum dots (GQDs) to dope polypyrrole (PPY), where GQDs-doped PPY as CE for DSSCs achieved a power conversion efficiency (PCE) of $5.27 \%$, being superior to that of PPY (4.46\%). Such an idea would be a promising and efficient strategy to further extend and boost the electrochemical performance of CoS-derived CE material.

In the present work, we report a strategy to synthesize CoS nanosheets coupled GQDs architecture via facile electrodeposition and sulfuration treatment. When employed as the DSSCs CE material, 7.30\% of conversion efficiency is delivered, being superior to those of $\mathrm{Pt}$ and $\mathrm{CoS}$, indicative of GQDs-promoted behaviors for DSSCs.

\section{EXPERIMENTAL SECTION}

\section{Preparation of graphene oxide (GO)}

3000 mesh GO was obtained by Hummer method. Briefly, $5 \mathrm{~g} 3000$ mesh graphite, $2.5 \mathrm{~g} \mathrm{NaNO}_{3}$ and $130 \mathrm{~mL}$ concentrated $\mathrm{H}_{2} \mathrm{SO}_{4}$ were stirred in the ice bath for $2 \mathrm{~h}$. $15 \mathrm{~g}$ $\mathrm{KMnO}_{4}$ were added slowly to ensure the temperature lower than $10^{\circ} \mathrm{C}$. Then, the mixture was kept at $35^{\circ} \mathrm{C}$ for $1 \mathrm{~h}$. After that, $230 \mathrm{~mL}$ deionized (DI) water was dropped slowly. The solution was stirred for $30 \mathrm{~min}$ at $98^{\circ} \mathrm{C}$ and then $400 \mathrm{~mL} \mathrm{DI}$ water and $10 \mathrm{~mL} \mathrm{H}_{2} \mathrm{O}_{2}$ were added to stop the reaction. At last, the GO solution was washed and centrifuged several times.

\section{Preparation of CE}

Graphene $(\mathrm{G})$ was prepared by thermal reduction of $\mathrm{GO}$ at $500^{\circ} \mathrm{C}$ for $2 \mathrm{~h}$ with a $5^{\circ} \mathrm{C} \mathrm{m^{-1 }}$ heating rate in $\mathrm{N}_{2}$ atmosphere. $160 \mathrm{mg} \mathrm{G}$ and $80 \mathrm{~mL}$ concentrated $\mathrm{HNO}_{3}$ were mixed and reacted at $120^{\circ} \mathrm{C}$ for $24 \mathrm{~h}$. The solution was separated by heating to $160^{\circ} \mathrm{C}$ to remove $\mathrm{HNO}_{3}$. The solid was diluted by DI water and sonicated for $30 \mathrm{~min}$. GQDs were obtained by dialyzing ( $3500 \mathrm{Da}$ ) the filtrate from filtering the above solution through $0.22 \mu \mathrm{m}$ membrane. $12 \mathrm{mg}$ GQDs and $20 \mathrm{mg} \mathrm{Co}\left(\mathrm{CH}_{3} \mathrm{COO}\right)_{2}$ were mixed and diluted to $30 \mathrm{~mL}$. After being sonicated for $10 \mathrm{~min}$, the electrodeposition was carried out in the above solution with a two electrode system at $2 \mathrm{~V}$ for $30 \mathrm{~min}$, in which washed fluorine doped tin oxide (FTO) was used as the anode and $\mathrm{Pt}$ electrode as the cathode. Finally, the FTO was dried in the ambient condition after being immersed in the $0.03 \mathrm{~mol} \mathrm{~L}^{-1}$ $\mathrm{Na}_{2} \mathrm{~S}$ solution for $10 \mathrm{~min}$. The whole fabrication process is illustrated in Scheme 1.

\section{Assembly of DSSCs}

DSSCs were fabricated according to our previous work [11]. The $\mathrm{TiO}_{2}$ photoanode purchased from OPV Tech New Energy Co., Ltd., China, was immersed into $0.6 \mathrm{mg} \mathrm{mL}^{-1}$ N719 (Solaronix SA, Switzerland) alcohol solution for 24 h. Then, the sensitized $\mathrm{TiO}_{2}$ photoanode was assembled with CE and sealed with hot-melt Surlyns (Surlyn, Yingkou OPV Tech New Energy Co., Ltd, China) to make the stand-

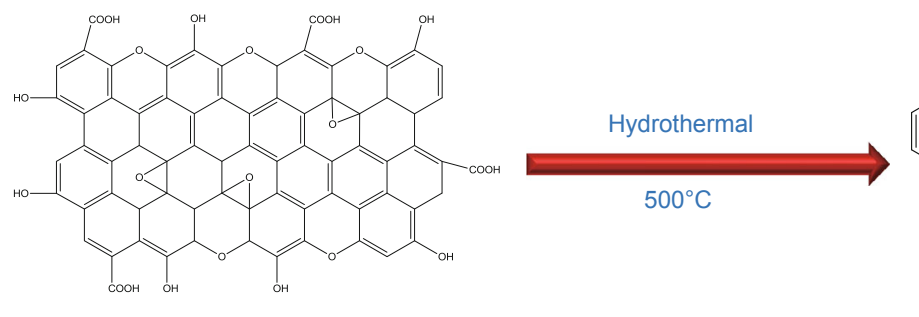

GO
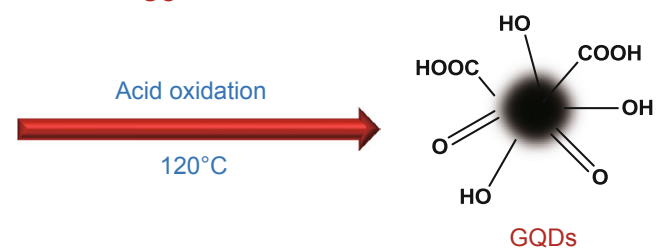

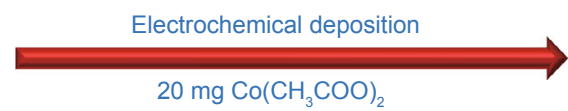

$20 \mathrm{mg} \mathrm{Co}\left(\mathrm{CH}_{3} \mathrm{COO}\right)_{2}$

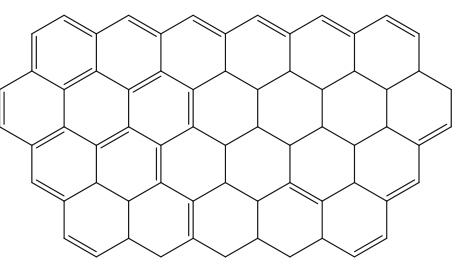

G

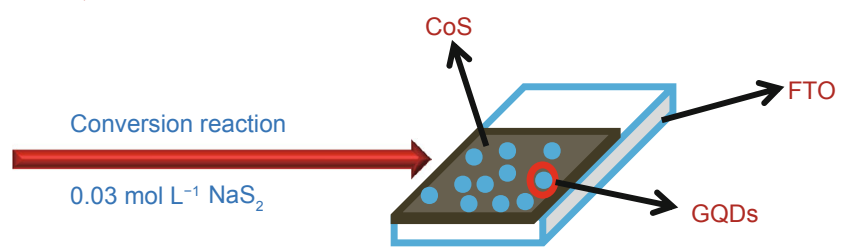

Scheme 1 Fabrication process of CoS-GQDs CE. 
ard sandwich-type configuration. Electrolyte (OPV-AN-I, Yingkou OPV Tech New Energy Co., Ltd., China) containing $0.1 \mathrm{mmol} \mathrm{L}^{-1} \mathrm{LiClO}_{4}, 10 \mathrm{mmol} \mathrm{L}^{-1} \mathrm{LiI}$ and $1 \mathrm{mmol} \mathrm{L}^{-1}$ $\mathrm{I}_{2}$ was injected into the DSSCs device with vacuum assistance. The sealed cells were used for the photocurrent-voltage test with an active area of $0.16 \mathrm{~cm}^{2}$.

\section{Characterization methods}

The ultraviolet-visible (UV-vis) characterization was carried out at room temperature on a Thermo Evolution 220 UV-visible spectrophotometer. For photoluminescence (PL) performance, the excitation spectra were recorded by using the Thermo Lumina Fluorescence Spectrometer. The surface morphology and composition were characterized by field-emission scanning electron microscopy (FESEM, FEI Nova Nano SEM 450) combined with an energy dispersive spectrometer (EDS). Transmission electron microscopy (TEM) images were obtained by using a Philips Tecnai G220. High resolution transmission electron microscopy (HRTEM) observations were made via FEI TF30. $\mathrm{X}$-ray diffraction (XRD) patterns were measured by a $\mathrm{D} /$ Max-2400 with $\mathrm{Cu} \mathrm{K}$ radiation $(\lambda=1.5406 \AA)$. X-ray photoelectron spectra (XPS, ESCALAB MK II X-ray) were conducted to analyze the surface properties.

\section{Electrochemical measurement}

The photocurrent-voltage $(J-V)$ curves were investigated by using a stimulated AM 1.5 illumination ( $I=100$ $\mathrm{mW} \mathrm{cm}{ }^{-2}$, PEC-L15, Peccell, Yokohama, Japan) equipped with a Keithley digital source meter (Keithley 2601). Tafel polarization curves and electrochemical impedance spectroscopic (EIS) characterization were conducted with a dummy cell. The former was carried out by a electrochemical workstation (CHI660D, Chenhua, Shanghai) at a scan rate of $10 \mathrm{mV} \mathrm{s}^{-1}$ while the latter was conducted with a computer-controlled potentiostat (Zenium Zahner, Kronach, Germany) at $0.8 \mathrm{~V}$ from $0.1 \mathrm{~Hz}$ to $1 \mathrm{MHz}$ with $10 \mathrm{mV}$ amplitude of the alternating current in ambient condition.
Cyclic voltammetry (CV) experiment was carried out with a scan rate of $10 \mathrm{mV} \mathrm{s}^{-1}$ in a three-electrode system, where the CoS-GQDs was used as the working electrode, Pt as the $\mathrm{CE}$, and $\mathrm{Ag} / \mathrm{Ag}^{+}$as the reference electrode in an acetonitrile solution containing $0.1 \mathrm{~mol} \mathrm{~L}^{-1} \mathrm{LiClO}_{4}, 10 \mathrm{mmol} \mathrm{L}-1 \mathrm{LiI}$, and $1 \mathrm{mmol} \mathrm{L}^{-1} \mathrm{I}_{2}$.

\section{RESULTS AND DISCUSSION}

The representative morphology and structure of the asmade GQDs are shown in Fig. 1. It can be clearly seen that the GQDs with a uniform size and shape distribution are produced (Fig. 1a). Further HRTEM images (insets of Figs $1 \mathrm{a}$ and $\mathrm{b}$ ) reveal that the GQDs have a lattice spacing of $0.22 \mathrm{~nm}$, which is associated with the (100) crystal plane of graphite crystallites. The Gaussian fitting curve (Fig. 1c) further indicates that the as-made GQDs can be well-dispersed with an average size of $1.59 \mathrm{~nm}$.

The optical features of the as-obtained GQDs were examined by UV-vis absorption and PL spectroscopy, and the detailed results are shown in Fig. 2. It can be clearly seen from Fig. 2a that the UV-vis spectrum shows two absorption peaks corresponding to the $\pi-\pi^{*}$ transition at ca. 230 $\mathrm{nm}$ and $\mathrm{n}-\pi^{*}$ at ca. $270 \mathrm{~nm}$, respectively [23]. To further evaluate the optical properties of the as-prepared GQDs, detailed PL study was carried out with different excitation wavelengths. As shown in Fig. 2b, the as-made GQDs display nearly an excitation-dependent PL behavior, which conforms to Stokes Law.

The typical top-view SEM images of CoS and CoSGQDs are shown in Fig. S1. It can be clearly seen that nanosheet-shaped interconnected networks-structured CoS uniformly and vertically grows on FTO glass substrate. Compared with CoS nanosheets, it is interesting that the relatively small-sized CoS nanosheets are clearly observed in the presence of GQDs. This indicates that GQDs modulate and tailor the growth behaviors of CoS nanosheets. The reason for this is that the functional groups on the surface of negative charged GQDs (Fig. S2) would be favour-
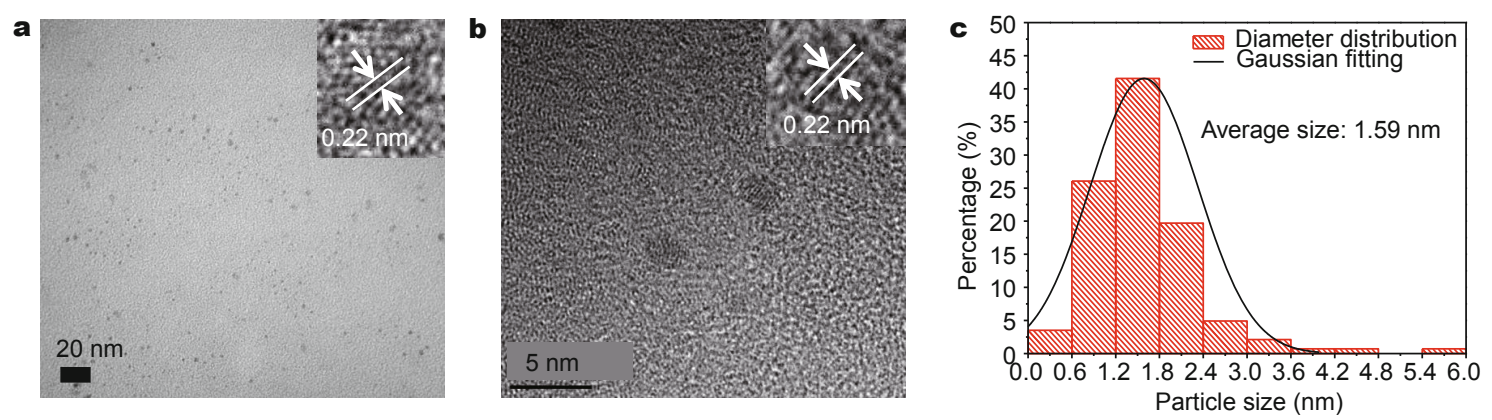

Figure 1 TEM of GQDs (a, b) (insets: HRTEM of GQDs), and the diameter distribution of GQDs (c). 

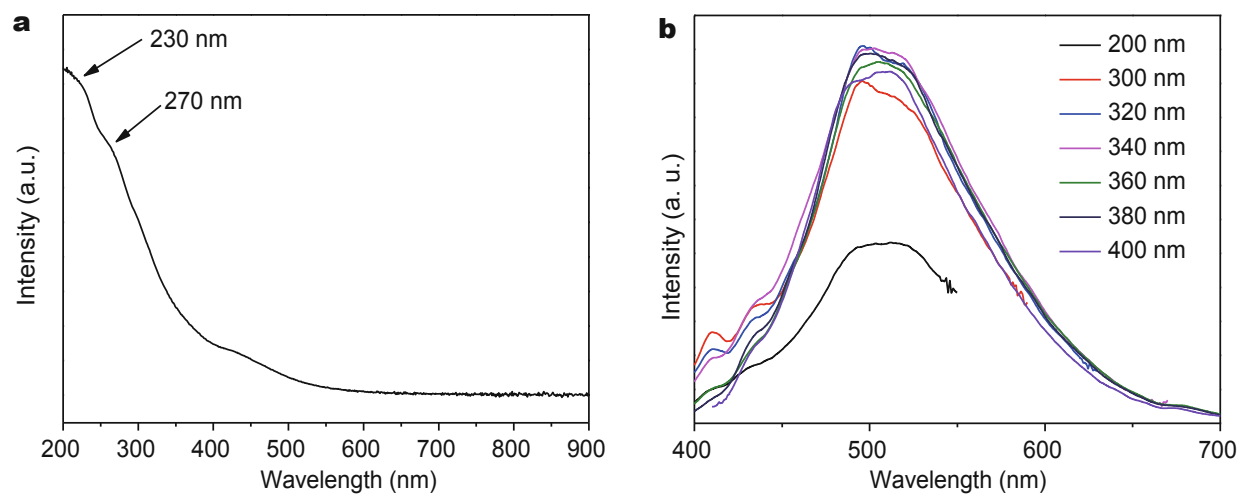

Figure 2 UV-vis absorption of GQDs (a), and PL emission spectra of GQDs at different excitation wavelengths (b).
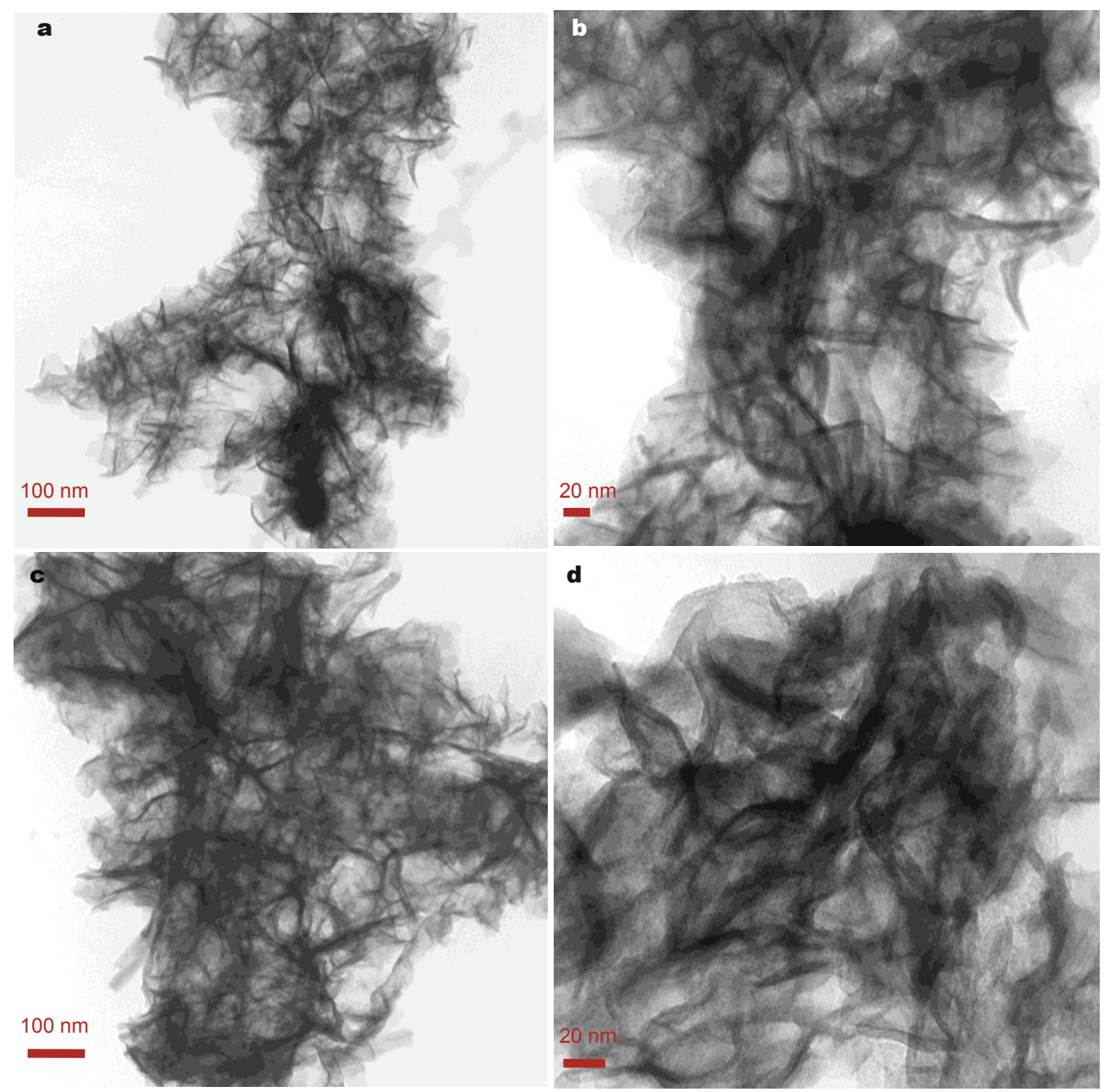

Figure 3 TEM images of $\operatorname{CoS}(a, b)$ and CoS-GQDs $(c, d)$.

able for providing more anchored active sites for adsorbing cobalt ions. In this case, the nucleation and growth of CoS nanosheets can be easily modulated and tailored, leading to more uniform structure and small-sized CoS. Further
TEM images shown in Fig. 3 reveal that the CoS features sheet-shaped structure.

It can be clearly seen from Fig. 4a that GQDs and CoS interconnect with each other and the nano-sized GQDs 

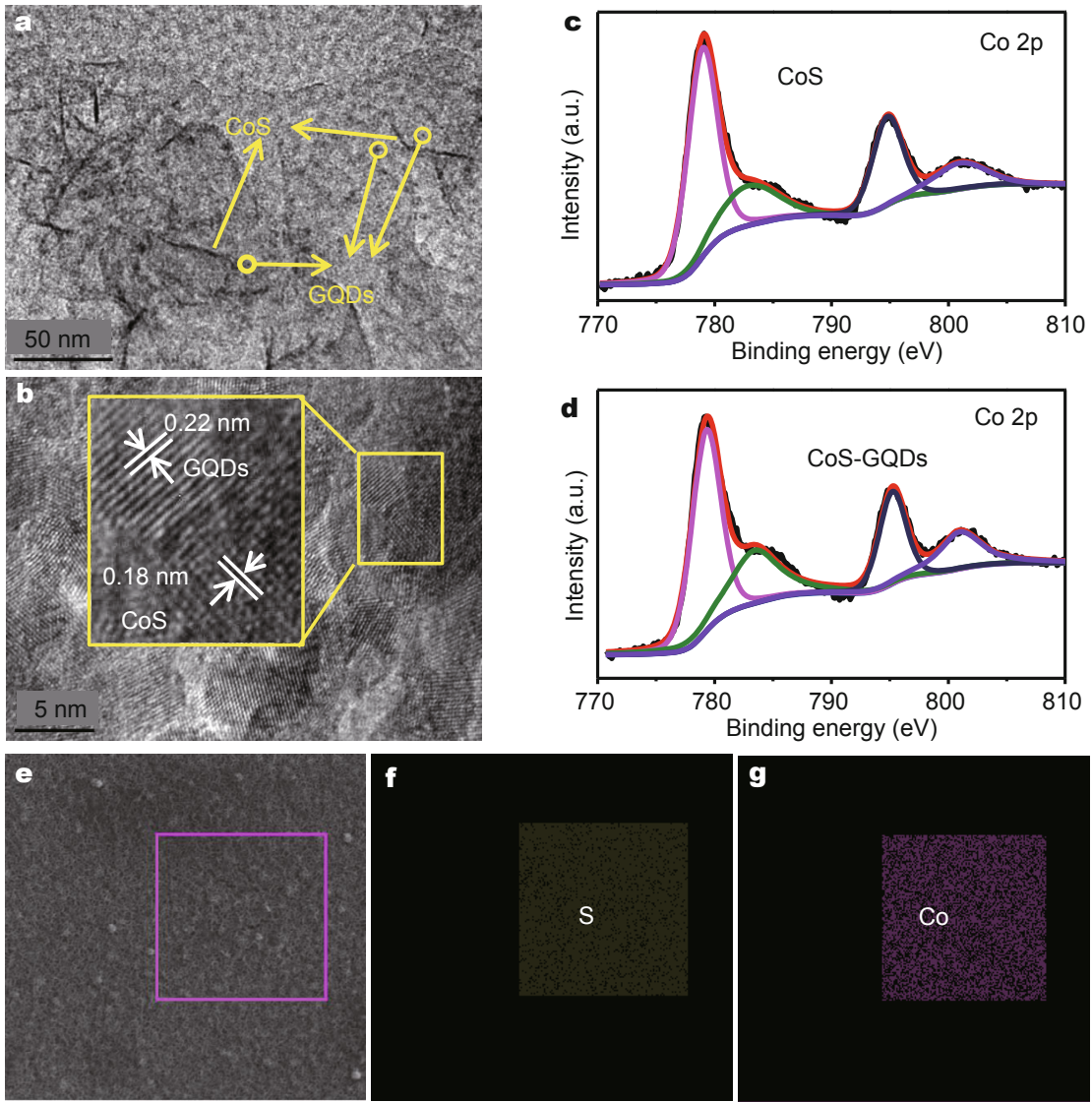

Figure 4 HRTEM images of CoS-GQDs (a, b), XPS spectra of CoS and CoS-GQDs (c, d) and EDS mapping of the as-prepared CoS-GQDs (e-g).

can be clearly observed within the matrix. HRTEM images shown in Fig. $4 \mathrm{~b}$ further reveal that the CoS has a lattice spacing of $0.18 \mathrm{~nm}$, while that of the GQDs is $0.22 \mathrm{~nm}$, which is in agreement with that of the pristine GQDs. No obvious differences are observed in the corresponding XPS spectra of $\mathrm{CoS}$ and CoS-GQDs (Figs 4c and d), implying that the addition of GQDs could not alter the Co valence at all. EDS mapping of CoS-GQDs in Figs $4 \mathrm{e}-\mathrm{g}$ demonstrate that $\mathrm{Co}$ and $\mathrm{S}$ species uniformly disperse on FTO glass substrate.

The electrocatalytic performances of CoS, CoS-GQDs, and $\mathrm{Pt}$ were evaluated, and the detailed results are shown in Fig. 5. The corresponding electrochemical parameters derived from CV curves are listed in Table S1. The two pairs of typical redox peaks that correlate with two reactions: $\mathrm{I}_{3}{ }^{-}$ $+2 \mathrm{e} \leftrightarrow 3 \mathrm{I}^{-}$and $3 \mathrm{I}_{2}+2 \mathrm{e} \leftrightarrow 2 \mathrm{I}_{3}^{-}$, respectively, can be clearly seen for all samples in Fig. 5a. The lower potential peaks are associated with the reaction of $\mathrm{I}_{3}^{-}+2 \mathrm{e} \leftrightarrow 3 \mathrm{I}^{-}$, while the potential peaks at higher voltage correspond to the reaction of $3 \mathrm{I}_{2}+2 \mathrm{e} \leftrightarrow 2 \mathrm{I}_{3}{ }^{-}$. The intensity of characteristic peak of $A_{\text {red }}$ and the separation between $A_{\mathrm{ox}}$ and $A_{\text {red }}$ peaks $\left(E_{\mathrm{pp}}\right)$ corre- spond to the catalytic activity of CEs towards the reduction of $\mathrm{I}_{3}{ }^{-}[5,24]$. The high peak current densities and low $E_{\mathrm{pp}}$ are responsible for the excellent electrocatalytic activity. It can be clearly seen that among the electrodes tested, the CoSGQDs electrode delivers the largest current density and lowest $E_{\mathrm{pp}}$ to some extent. This indicates that the as-made CoS-GQDs can most effectively reduce $\mathrm{I}_{3}{ }^{-}$to $\mathrm{I}^{-}$.

The EIS measurements reflecting the electrochemical characteristics were performed and the corresponding $\mathrm{Ny}-$ quist plots are displayed in Fig. 5b. The detailed parameters obtained by fitting the plots with the equivalent circuit (Fig. S3) are also summarized in Table S1. As shown, CoS, CoSGQDs, and Pt exhibit the similar $R_{\mathrm{s}}$ values, indicating the similar bonding strength between the CEs and conducting glass substrate. Besides, the CoS-GQDs electrode also gives the lowest $R_{\mathrm{ct}}$ value, allowing a fast charge transfer at the interface of electrode/electrolyte. The excellent electrochemical characteristics may endow CoS-GQDs with a promising substitute for Pt CE of DSSCs. Fig. $5 \mathrm{c}$ shows the Tafel polarization curves that the variation of logarithmic current density $(\log J)$ is plotted against the voltage. It can 

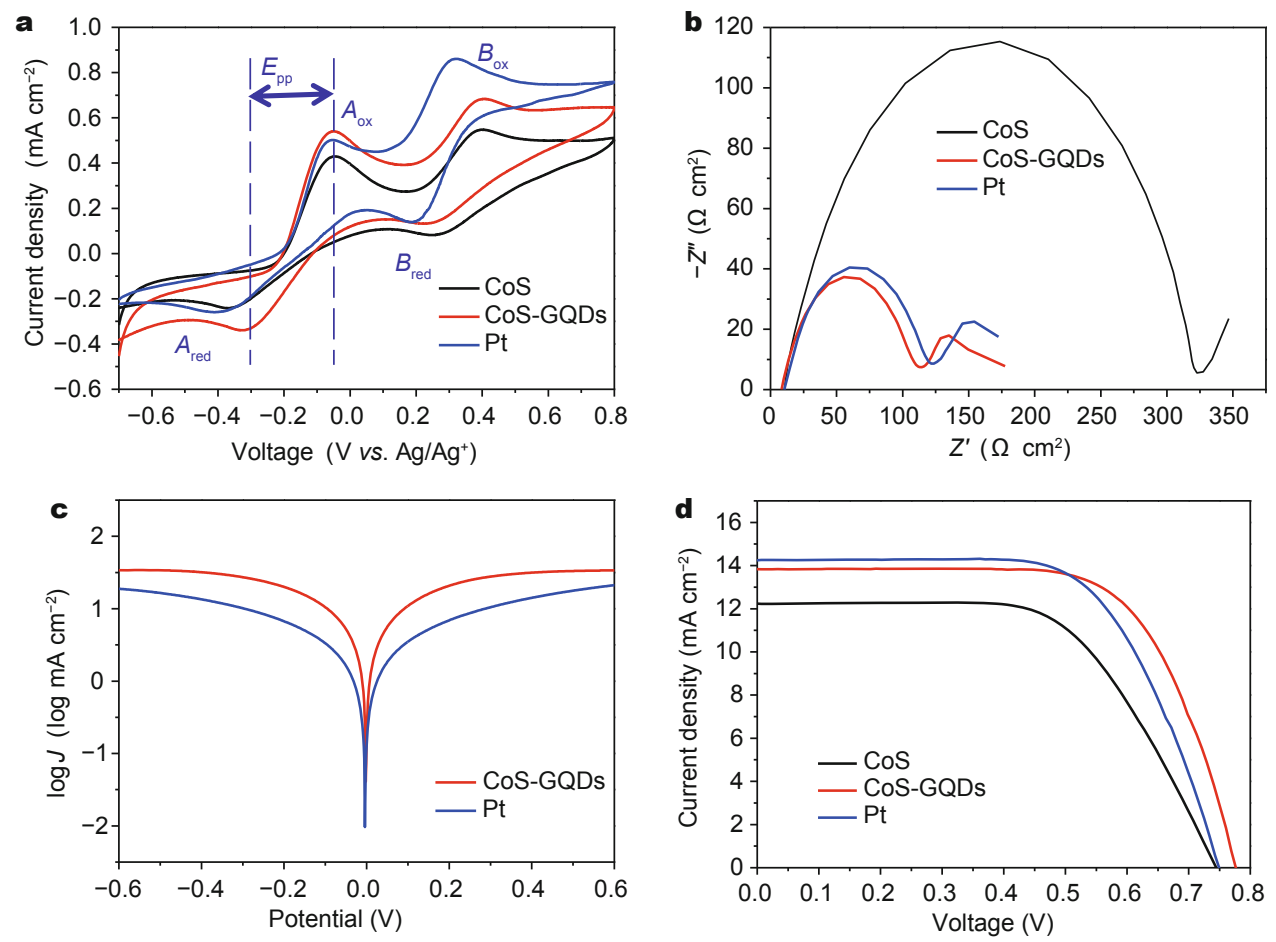

Figure 5 (a) CV curves for CoS, CoS-GQDs, and Pt; (b) Nyquist plots of DSSCs based with CoS, CoS-GQDs, and Pt; (c) Tafel curves of symmetric CoS, CoS-GQDs and Pt electrode; (d) $J$ - $V$ curves of DSSCs based on CoS, CoS-GQDs, and Pt.

be clearly seen that the CoS-GQDs CE has relatively larger slope for the anodic or cathodic branch in polarization zone compared with that of Pt CE, indicating a higher exchange current density $\left(J_{0}\right)$ [25]. The high $J_{0}$ corresponds to low $R_{\mathrm{c} \text { t }}$ which is in good agreement with EIS's results above. This implies that the CoS-GQDs can more effectively catalyze the reduction of $\mathrm{I}_{3}{ }^{-}$to $\mathrm{I}^{-}$. The $J-V$ curves of the DSSCs based on CoS, CoS-GQDs and Pt tested under simulated sunlight is demonstrated in Fig. 5d, and the corresponding parameters of photovoltaic device performance are listed in Table 1. The CoS-GQDs electrode shows a short-circuit photocurrent $\left(J_{\mathrm{sc}}\right)$ of $13.83 \mathrm{~mA} \mathrm{~cm}{ }^{-2}$, an open-circuit voltage $\left(V_{\text {oc }}\right)$ of $0.78 \mathrm{~V}$, and a fill factor $(F F)$ of $68 \%$, thus yielding a conversion efficiency of $7.30 \%$. While the Pt electrode only shows the conversion efficiency of 6.94\%, indicative of the superior performance of CoS-GQDs CE for DSSCs. It is also noted that the CoS electrode only exhibits a conver- sion efficiency of 5.55\%, further revealing unique function of GQDs in this system.

\section{CONCLUSIONS}

In summary, CoS-GQDs hybrids were successfully configured via electrodepositing GQDs and CoS on the FTO glass substrate. The functional groups on the surface of negative charged GQDs would provide more anchored active sites for adsorbing cobalt ions, thus modulating and tailoring the nucleation and growth behaviors of $\operatorname{CoS}$ nanosheets. When applied as the binder-free CE for DSSCs, the asmade CoS-GQDs exhibit a high catalytic activity towards the reduction of $\mathrm{I}_{3}^{-}$, and $7.30 \%$ of PCE is delivered, being superior to those of $\mathrm{Pt}$ and $\mathrm{CoS}$. Such a high performance would be attributed to synergetic effects of GQDs and CoS. The present work provides a simple method for configuring low-cost binder-free CE materials for replacing Pt.

Table 1 Photovoltaic and electrochemical parameters of CoS, CoS-GQDs and Pt CEs

\begin{tabular}{ccccc}
\hline $\mathrm{CE}$ & $V_{\mathrm{oc}}(\mathrm{V})$ & $J_{\mathrm{sc}}\left(\mathrm{mA} \mathrm{cm}^{-2}\right)$ & $F F(\%)$ & $\eta(\%)$ \\
\hline $\mathrm{CoS}$ & $0.74 \pm 0.03$ & $12.23 \pm 0.14$ & $61 \pm 0.4$ & $5.55 \pm 0.10$ \\
CoS-GQDs & $0.78 \pm 0.03$ & $13.83 \pm 0.13$ & $68 \pm 0.5$ & $7.30 \pm 0.13$ \\
$\mathrm{Pt}$ & $0.75 \pm 0.02$ & $14.25 \pm 0.18$ & $65 \pm 0.1$ & $6.94 \pm 0.05$ \\
\hline
\end{tabular}


Received 21 January 2016; accepted 12 February 2016; published online 29 February 2016

1 Zhu W, Wu Y, Wang S, et al. Organic D-A- $\pi$-A solar cell sensitizers with improved stability and spectral response. Adv Funct Mater, 2011, 21: 756-763

2 Wang H, Sun K, Tao F, et al. 3D honeycomb-like structured graphene and its high efficiency as a counter-electrode catalyst for dye-sensitized solar cells. Angew Chem Int Ed, 2013, 125: 93809384

$3 \mathrm{Xu} \mathrm{XB}$, Huang DK, Cao $\mathrm{K}$, et al. Electrochemically reduced graphene oxide multilayer films as efficient counter electrode for dye-sensitized solar cells. Sci Rep, 2013, 3: 1489

4 O'regan B, Grätzel M. A low-cost, high-efficiency solar cell based on dye-sensitized colloidal $\mathrm{TiO}_{2}$ films. Nature, 1991, 353: 737-740

5 Meng XT, Yu C, Song XD, et al. Nitrogen-doped graphene nanoribbons with surface enriched active sites and enhanced performance for dye-sensitized solar cells. Adv Energy Mater, 2015, 5: 1500180

6 Wang GQ, Zhuo SP. Hierarchical micro/nano-structured cobalt sulfide spindles as low-cost counter electrodes for dye-sensitized solar cells. Phys Chem Chem Phys, 2013, 15: 13801-13804

7 Xin XK, He M, Han W, et al. Low-cost copper zinc tin sulfide counter electrodes for high-efficiency dye-Sensitized solar cells. Angew Chem Int Ed, 2011, 50: 11739-11742

8 Wu MX, Lin X, Wang YD, et al. Economical Pt-free catalysts for counter electrodes of dye-sensitized solar cells. J Am Chem Soc, 2012, 134: 3419-3428

9 Tang QW, Cai HY, Yuan SS, et al. Counter electrodes from double-layered polyaniline nanostructures for dye-sensitized solar cell applications. J Mater Chem A, 2013, 1: 317-323

10 Wu MX, Lin X, Wang TH, et al. Low-cost dye-sensitized solar cell based on nine kinds of carbon counter electrodes. Energy Environ Sci, 2011, 4: 2308-2315

11 Fang HQ, Yu C, Ma TL, et al. Boron-doped graphene as a high-efficiency counter electrode for dye-sensitized solar cells. Chem Commun, 2014, 50: 3328-3330

12 Xiao YM, Lin JY, Wu JH, et al. Dye-sensitized solar cells with high-performance polyaniline/multi-wall carbon nanotube counter electrodes electropolymerized by a pulse potentiostatic technique. J Power Sources, 2013, 233: 320-325

13 Huang GC, Chen T, Wang Z, et al. Synthesis and electrochemical performances of cobalt sulfides/graphene nanocomposite as anode material of Li-ion battery. J Power Sources, 2013, 235: 122-128

14 Dai K, Li DP, Lu LH, et al. Facile synthesis of a reduced graphene oxide/cobalt sulfide hybrid and its electrochemical capacitance performance. RSC Adv, 2014, 4: 29216-29222

15 Wan HZ, Ji X, Jiang JJ, et al. Hydrothermal synthesis of cobalt sul- fide nanotubes: the size control and its application in supercapacitors. J Power Sources, 2013, 243: 396-402

16 Miao XH, Pan K, Wang GF, et al. Well-dispersed CoS nanoparticles on a functionalized graphene nanosheet surface: a counter electrode of dye-sensitized solar cells. Chem Eur J, 2014, 20: 474-482

17 Kung CW, Chen HW, Lin CY, et al. CoS acicular nanorod arrays for the counter electrode of an efficient dye-sensitized solar cell. ACS Nano, 2012, 6: 7016-7025

$18 \mathrm{Xu}$ XY, Ray R, Gu YL, et al. Electrophoretic analysis and purification of fluorescent single-walled carbon nanotube fragments. J Am Chem Soc, 2004, 126: 12736-12737

$19 \mathrm{Hu}$ C, Yu C, Li MY, et al. Chemically tailoring coal to fluorescent carbon dots with tuned size and their capacity for $\mathrm{Cu}$ (II) detection. Small, 2014, 10: 4926-4933

20 Chen LJ, Guo CX, Zhang QM, et al. Graphene quantum-dot-doped polypyrrole counter electrode for high-performance dye-sensitized solar cells. ACS Appl Mater Interfaces, 2013, 5: 2047-2052

$21 \mathrm{Hu}$ Y, Zhao Y, Lu G, et al. Graphene quantum dots-carbon nanotube hybrid arrays for supercapacitors. Nanotechnology, 2013, 24: 195401

$22 \mathrm{Hu}$ C, Yu C, Li MY, et al. Nitrogen-doped carbon dots decorated on graphene: a novel all-carbon hybrid electrocatalyst for enhanced oxygen reduction reaction. Chem Commun, 2015, 51: 3419-3422

23 Lin YY, Chapman R, Stevens MM. Integrative self-assembly of graphene quantum dots and biopolymers into a versatile biosensing toolkit. Adv Funct Mater, 2015, 25: 3183-3192

24 Zheng XJ, Deng J, Wang N, et al. Podlike N-doped carbon nanotubes encapsulating FeNi alloy nanoparticles: high-performance counter electrode materials for dye-sensitized solar cells. Angew Chem Int Ed, 2014, 53: 7023-7027

25 Wu MX, Lin X, Hagfeldt A, et al. Low-cost molybdenum carbide and tungsten carbide counter electrodes for dye-sensitized solar cells. Angew Chem Int Ed, 2011, 50: 3520-3524

Acknowledgements This work was supported by the National Natural Science Foundation of China (21361162004 and U1203292) and the Education Department of the Liaoning Province of China (T2013001).

Author contributions Yu C and Qiu J directed and designed the project. Liu Z and Chen Y performed the experiments. Meng X and Li M contributed to the strategy optimization. Yu C and Liu $\mathrm{Z}$ analyzed the results and wrote the paper. All authors contributed to the general discussion.

Conflict of interest The authors declare that they have no conflict of interest.

Supplementary information Supporting data are available in the online version of the paper. 


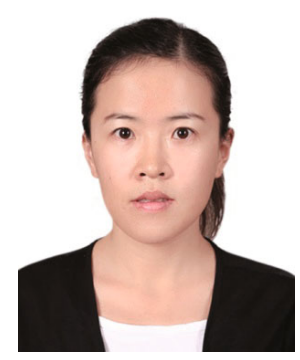

Chang Yu received her PhD degree from the School of Chemical Engineering at Dalian University of Technology (DUT) in 2008. She is currently a professor at DUT. Her research interests mainly focus on carbon coupled two-dimensional inorganic layered materials for energy storage and conversion applications.

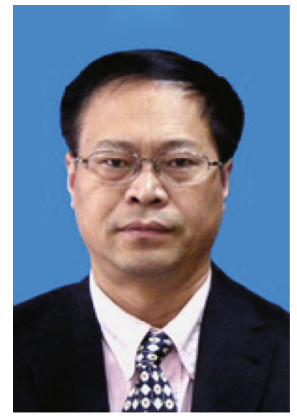

Jieshan Qiu received his PhD degree from the School of Chemical Engineering at DUT in China. He was appointed to a Cheung-Kong Distinguished Professor in 2009. He is a professor of the School of Chemical Engineering and director of the Carbon Research Laboratory at DUT. His current research includes functional carbon nanotubes, graphene, carbon nanohybrids, and their applications (energy conversion and storage, capacitive deionization technique, etc.).

\section{硫化钴纳米片耦合石墨烯量子点构筑优异的染料敏化太阳能电池无粘结剂对电极}

于畅, 刘志强, 陈毅文, 孟祥桐, 李明宇, 邱介山

摘要 染料敏化太阳能电池(DSSCs)因其造价低、稳定性高、工艺简单, 备受关注. 廉价对电极材料的设计与构筑是亟需解决的关键科学问题之 一. 本文采用电沉积技术, 在FTO玻璃基底上制备了硫化钴纳米片-石墨烯量子点复合结构纳米材料, 研究了其直接作为DSSCs对电极材料的催 化性能和光电转换效率. 结果发现, 该材料对 $\mathrm{I}_{3}{ }^{-}$的还原表现出较高的催化性能, 光电转换效率达 $7.30 \%$, 优于单一的硫化钴(5.55\%)和商业化的贵 金属铂催化剂(6.94\%). 本研究为廉价、可取代铂的无粘结剂电极材料的开发提供了一个有效的途径. 